\title{
The effects of isolation and handling on reactivity to footshock and tactile dorsal stimulation
}

\author{
RICHARD J. VIKEN, DANNY L. MOORE, JOHN F. KNUTSON, \\ and DAVID J. FORDYCE \\ University of Iowa, Iowa City, Iowa
}

\begin{abstract}
The effects of isolation and handling on the reactivity of rats to two tactile stimuli were assessed in two experiments. In the first experiment, reactivity to more intense footshock was increased in rats raised in isolation but was not affected by handling by an experimenter. In the second experiment, increased reactivity to airpuff stimuli presented to the dorsal surface of isolation-reared rats was reduced by handling. The data suggest that the effects of handling on shock-motivated behaviors are not due to altered reactivity to shock and that the effect of housing or handling must be considered in behavioral tests in which reactivity to tactile stimulation might play a role as dependent or independent variables.
\end{abstract}

Housing in isolation is a routine procedure for maintaining laboratory animals during experimentation. Isolation-rearing and housing is also an independent variable that has been investigated widely in behavioral and physiological studies. In addition to affecting gonadal and adrenocortical functions of rats (e.g., Brain \& Nowell, 1971; Dessí-Fulgheri, Lupo di Prisco, \& Verdarelli, 1975; Goldsmith, Brain, \& Benton, 1976), isolation has been shown to influence such behaviors as habituation (e.g., Einon, Morgan, \& Kibbler, 1978), irritability in septal-lesioned animals (Ahmad \& Harvey, 1968), and aggression (e.g., Adams, 1976; Flannelly \& Thor, 1976; Hutzell \& Knutson, 1972; Knutson \& Kane, 1980; Luciano $\&$ Lore, 1975). One of the interesting aspects of the effects of isolation on behavior is the inconsistency to be found in the aggression literature. While some studies of resident-intruder aggression indicate that isolation results in more aggressive responding (e.g., Flannelly \& Thor, 1976; Luciano \& Lore, 1975), studies of shock-induced aggression suggest that less aggression can be associated with isolation housing (e.g., Hutzell \& Knutson, 1972; Knutson \& Kane, 1980). Because different paradigms are used, it is possible that the inconsistencies reflect different kinds of aggression (cf. Moyer, 1968) and the effect of different variables. It is also possible that isolation affects various behaviors differently. Cairns (1973) and Welch and Welch (1971) suggest that animals maintained in isolation are hyperreactive to tactile

The contribution of David Gause to the development of the airdelivery apparatus and the assistance of John G. Mehm in the collection of data are gratefully acknowledged. Reprints may be obtained from John F. Knutson, Department of Psychology, University of Iowa, Iowa City, Iowa 52242. stimulation and that the hyperreactivity could mediate some of the behavioral characteristics of isolated rats. It is conceivable that greater reactivity in some behavioral tests (e.g., resident-intruder paradigm) could facilitate a response and that greater reactivity in other circumstances (e.g., shock-induced aggression paradigm) could impair performance.

Handling is another routine laboratory procedure (cf. Christie, 1951; Levis, 1970) that has also been investigated as an independent variable that might affect the reactivity of rats. Just as isolation has been shown to affect adrenocortical activity and to have inconsistent effects of behavior, handling has been shown to affect adrenocortical function (e.g., Bartness \& Waldbillig, 1981; Bassett, Cairncross, \& King, 1973; Hennessy \& Levine, 1978; Hennessy, Levine, \& Levine, 1977) and to have inconsistent behavioral effects. For example, although some investigators (e.g., Altman \& Hommel, 1969; Harlow \& Zimmermann, 1959) have described handling as having a calming effect on animals, other studies have demonstrated the aversive properties of handling and gentling (e.g., Candland, Faulds, Thomas, \& Candland, 1960; Candland, Horowitz, \& Culbertson, 1962). The presumed calming effect of an aversive stimulus (handling) is especially interesting in the context of the effects of handling on shock-motivated behavior. Although Altman and Hommell (1969) demonstrated that handling reduced avoidance responding in an approach-avoidance conflict test and Levis (1970) demonstrated that handling facilitated extinction of the one-way avoidance response, other studies have indicated that handling improves the acquisition of shuttle avoidance (e.g., Theios, Lynch, \& Lowe, 1966; Wahlsten \& Sharp, 1969) and barpress avoidance (e.g., Wahlsten, Cole, Sharp, \& 
Fantino, 1968). Furthermore, the handling that occurs between trials in the one-way avoidance paradigm has been considered a factor that contributes to the marked differences in acquisition rate between one-way and shuttle avoidance tasks (e.g., Theios et al., 1966; Wahlsten \& Sharp, 1969). Interestingly, the performance in escape from fear conditioning of rats handled by the body in the intertrial interval improves over that of rats handled by the tail in the intertrial interval (McAllister, McAllister, Hampton, $\&$ Scoles, 1980). Because of the attenuation of freezing and the increased activity that has been noted in handled animals (cf. Bernstein, 1957; Sperling \& Valle, 1964), altered activity and reduced freezing have been hypothesized to account for the effects of handling on shock-motivated behavior, although altered reinforcer effectiveness (McAllister et al., 1980) has also been suggested.

Although attenuated freezing, increased activity, or altered reinforcement effectiveness can be used to account for some of the differences between handled and unhandled rats in shock-motivated tasks, it is possible that these patterns of responding reflect an altered reactivity to environmental stimuli, just as isolation or group housing alters reactivity. The purpose of the first experiment was to determine whether handling would alter the reactivity of rats to shock stimuli after their being raised and maintained in either isolation or group cages. Although Theios et al. (1966) demonstrated that handling improved shuttle performance relative to one-way avoidance responding, they argued that handling was an unlikely factor to account for the increasing difference between oneway and shuttle avoidance behavior as a function of shock level. No empirical evidence was provided. Consequently, the first experiment was also designed to determine whether the effect of handling on reactivity would interact with the intensity of the test stimuli.

\section{EXPERIMENT 1}

\section{Method}

Subjects. Twenty-four experimentally naive male hooded rats from the colony of the Department of Psychology at the University of lowa were used. All rats had been whelped and raised in a colony room under a 12-h-light/12-h-dark cycle (lights on from 0600 to $1800 \mathrm{~h}$ ). They had free access to food and water for the duration of the experiment. All subjects had been weaned at 22-23 days of age. Subjects from the isolation condition were housed individually in $24 \times 20.3 \times 17.8 \mathrm{~cm}$ stainless steel and wire-mesh cages from weaning until the end of the experiment. Subjects from the group-housed condition were maintained 4-6 per cage in $24 \times 66 \times 17.8 \mathrm{~cm}$ cages from weaning until the end of the experiment.

Apparatus. To measure responsivity to shock, an isometric startle platform similar to that described by Cunningham, Crowell, Eaton, and Brown (1973) was used. The startle platform consisted of a $23 \times 27.5 \times 2.54 \mathrm{~cm}$ plywood board that was attached at one end to a $9.5 \times 23 \times 2.54 \mathrm{~cm}$ aluminum upright. The base of the aluminum upright was attached to a $41 \times 30.5 \times$ $3.1 \mathrm{~cm}$ plywood panel that was weighted with an $11-\mathrm{kg}$ bag of sand. A $7.9 \times 23 \times 20.2 \mathrm{~cm}$ test chamber, with walls and lid constructed of clear Plexiglas and a grid floor constructed of $.3-\mathrm{cm}$ diam stainless steel rods spaced $1.3 \mathrm{~cm}$ center to center, was attached to the startle platform by an aluminum frame that held the chamber $2.5 \mathrm{~cm}$ above the surface of the platform. On the lower surface of the startle platform, beneath the test chamber, an Astatic phono cartridge (No. 24) was attached to the startle platform. A $5.5-\mathrm{cm}$ brass rod weighing $.9 \mathrm{~g}$ was fitted into the stylus aperture of the phono cartridge so that it maintained a position parallel to the platform. The electrical output of the cartridge was passed through a solid-state peak-voltage detection circuit and was monitored by means of a Hewlett-Packard digital voltmeter. Since a greater amplitude response by a subject confined in the test chamber results in a greater voltage output of the cartridge, the peak voltage output provided a digital index of the reaction of a subject to the shock stimuli. Shock to the grid floor of the chamber was provided by a constant-current tube-type dc shock source. The entire startle platform was housed in an Industrial Acoustics Corporation (New York, N.Y.) $2.44 \times 2.44 \times 2.13 \mathrm{~m}$ sound-attenuating chamber.

Procedure. When the subjects were 120 days of age, half of the isolated and half of the group-housed animals were assigned to a handling condition, with the remaining subjects assigned to the control condition. Based on the procedure of Ahmad and Harvey (1968) for reducing the irritability of septal rats, the subjects in the handling condition were submitted to five daily handling sessions. On the first day, starting at $0900 \mathrm{~h}$, each handled rat was removed from its cage, marked on the tail with a felt-tipped marker, and gently massaged with a gloved hand for $3 \mathrm{~min}$. The handling procedure was repeated on succeeding days. Twenty-four hours after the final handling session, the rats from all conditions were tested for reactivity to shock stimuli. Individual subjects were placed in the test chamber and submitted to 40.5 -sec shocks at an intershock interval (onset to onset) of $20 \mathrm{sec}$. Equal numbers of shocks at intensities of 1 and $2 \mathrm{~mA}$ were employed, with the order of presentation randomized within the shock train. An experimenter, uninformed with respect to group membership, used the digital voltmeter to record the peak voltage output of the cartridge following each shock.

\section{Results and Discussion}

Reactivity scores were based on the mean voltage output for each rat at each of the two shock intensities. These reactivity scores were analyzed using a three-factor mixed analysis of variance, with betweensubjects factors of housing and handling and a withinsubject factor of shock intensity. The statistically significant housing $x$ shock intensity interaction is shown in Figure $1[\mathrm{~F}(1,20)=13.22, \mathrm{p}<.01]$. Analyses of simple effects indicated that there was a greater reaction to the 2-mA shock than to the $1-\mathrm{mA}$ one within both housing-condition groups. Tests of simple effects within shock levels indicated that the isolated groups were more reactive at both 1- and 2-mA shocks, although the difference between groups was markedly greater at $2 \mathrm{~mA}$ than at $1 \mathrm{~mA}$. These data are consistent with other research (e.g., Nelson \& Knutson, 1978) demonstrating that male rats housed in isolation react more to shock stimuli than do group-housed male rats and that the difference between groups is greater at higher shock intensities. The effect of handling did not approach statistical significance, and handling did not interact with the shock inten- 


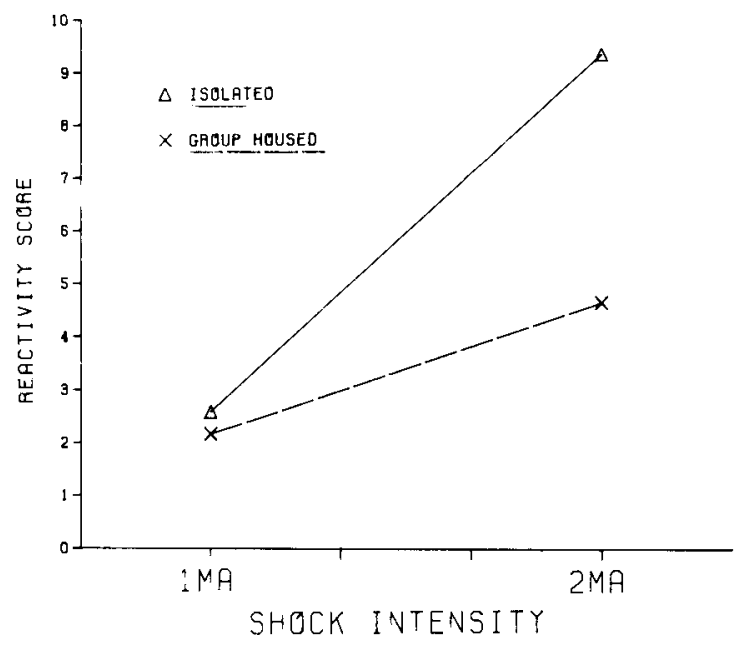

Figure 1. The mean responsivity scores of the housing condition groups of Experiment 1 at the two shock intensities. The responsivity score was the peak voltage output of the phono cartridge attached to the isometric startle platform.

sity. Although the greater reactivity of animals housed in isolation was demonstrated, the lack of a handling effect for reactivity to shock was not consistent with data showing altered avoidance conditioning as a function of handling (e.g., Levis, 1970; Wahlsten et al., 1968; Wahlsten \& Sharp, 1969). These data, then, suggest that the influence of gentling, or handling between trials, on tests of shock-motivated behavior is not due to differences in reactivity between handled and unhandled rats. Furthermore, these null effects of handling are not inconsistent with the Theios et al. (1966) position, which is that handling cannot be used to account for the interaction of shock intensity with performance in shuttle and one-way avoidance comparisons.

\section{EXPERIMENT 2}

While Experiment 1 demonstrated that handling did not influence the reactivity of isolated and grouphoused rats to shock stimuli, it is still possible that handling could affect reactivity to other tactile stimuli. Support for this possibility was provided by the Ahmad and Harvey (1968) demonstration that handling could affect the irritability syndrome of septallesioned rats without affecting the shock-induced aggressive behavior of those rats. Thus, it is possible that the various effects of handling on the performance of rats reflects the effects of handling on reactivity to some stimuli. The purpose of this experiment was to assess the effects of handling and isolation on reactivity to a nonpainful tactile stimulus.

To assess the reaction of laboratory animals to nonpainful tactile stimulation, experimenters often rate a subject's response to being touched by a pencil (e.g., Cain, 1974) or rod (e.g., Loizzo \& Massotti,
1973), resistance to capture and the reaction to being held in a gloved hand (e.g., Ahmad \& Harvey, 1968; Bandler \& Chi, 1972; Cain, 1974), or the reaction to being held with rubber-coated forceps (e.g., Slotnick \& McMullen, 1972). These procedures are not readily quantified, nor do they relate clearly to responses measured with the isometric startle platform used in Experiment 1. In light of these factors, a train of regularly presented airpuffs (Galvani, 1970) was selected as the tactile stimulation to assess reactivity.

\section{Method}

Subjects. Twenty-eight experimentally naive male hooded rats from the colony of the Department of Psychology at the University of Iowa were used. Employing procedures identical to those of Experiment 1 , the subjects were weaned at 23 days of age and housed either in isolation or in groups.

Apparatus. To measure reactions to airpuff stimuli in unrestrained rats, an isometric startle platform identical to that used in Experiment 1 was placed on the floor of a $50 \times 85 \times 52 \mathrm{~cm}$ (i.d.) sound-attenuating chamber in which the air delivery unit was mounted. The unit for delivering air to a subject confined in the test chamber on the startle platform consisted of a standard propane cast-iron drill-port burner (Burnham Corporation, Lancaster, $\mathrm{Pa}$.) that had been modified by removing the flanged opening and threading the remaining input tube with a 3/4-in. pipe die so that a standard coupling could be attached. Briefly, the burner consists of two parallel tapered cast-iron tubes connected at both ends. Each tube of the burner has 64 .076-in. $(1.93-\mathrm{mm})$ holes distributed in two 26-cm-long rows, separated $6.4 \mathrm{~mm}$ center to center. The double rows of holes on the parallel tubes were separated $3.175 \mathrm{~cm}$ center to center. With the burner mounted with the holes facing downward, the startle platform could be positioned directly beneath it, eliminating the need for a chamber lid and permitting air delivery to a rat at equal pressure regardless of the location and posture of the rat.

Compressed air was produced by a Henke Pacemaker twocylinder air compressor equipped with a 30-gal storage tank (Model HT44A, Henke Manufacturing, Milwaukee, Wis.). The 120-140 psi compressed air was passed through a Fulflo filter (Commercial Filter Corporation, Lebanon, Ind.) and then conducted through a $2-\mathrm{m} .5-\mathrm{in} .(1.27 \mathrm{~cm})$ high-pressure polyethylene hose to a Norgren pressure control valve that was used to control the intensity of the air delivered to the rat. Between the pressure control valve and the burner, a standard solenoid-operated gas valve controlled the onset and offset of airpuffs. The programming of the air delivery was accomplished using conventional timers and relay circuitry.

Because the air delivery results in a mechanical force on the startle platform and in noise, the measured reactivity of a rat to air delivery could be due to factors other than the tactile stimulation of the air. To assess the role of noise and the mechanical effects of air on the reactivity measure, two preliminary experiments were conducted.' The first, using 72 subjects in a factorial design, assessed the reactivity of experimentally naive adult male rats to airpuffs, at $5,10,20$, or $30 \mathrm{psi}$, and to the associated noise. In addition, a group of rats equal in weight to the rats of the other groups were sacrificed under a $\mathrm{CO}_{2}$ atmosphere. When placed in the chamber on the startle platform, each dead rat matched a rat from other experimental groups in terms of mass and air deflection properties, and the mechanical impact of the airpuffs on the startle platform at each test intensity was assessed. A threefactor mixed analysis of variance indicated that the monotonic increase in reactivity of the rats to the increasing intensity of airpuff stimuli was not due to the mechanical impact of air on the platform or to the reaction of the rats to the noise that accompanied air delivery. Furthermore, the data indicated that there was no adaptation to the air stimuli across 20 trials. The second 
preliminary experiment, using a within-subject design, replicated the increase in reactivity as a function of increasing airpuff intensities from 5 to 30 psi.

Procedure. When the subjects were 120 days of age, half (seven) of the isolated and half (seven) of the group-housed animals were assigned to a handling condition, with the remaining subjects of each group assigned to the control condition. Following the procedures of Experiment 1, subjects in the handling condition were marked with a color-coded band on the tail and submitted to five daily 3-min handling sessions starting at $0900 \mathrm{~h}$. Twenty-four hours after the final handling session, the rats were placed individually in the test chamber and tested for reactivity to the airpuff stimuli. Each rat was submitted to $28.1-\mathrm{sec}$ airpuffs with an interpuff interval of $20 \mathrm{sec}$, onset to onset. Seven airpuffs at each intensity of $5,10,20$, and 30 psi were presented, with the order determined by a table of random numbers. One experimenter set the air pressure for each puff presentation, and a second experimenter, uninformed with respect to the air pressure used and the group membership of the subject, recorded the peak voltage output of the phono cartridge following each puff presentation.

\section{Results and Discussion}

The analysis of reactivity to the airpuff stimuli was based on the mean voltage output recorded for each of the four airpuff intensities. These scores were analyzed in a three-factor mixed analysis of variance with housing and handling as between-subjects factors and airpuff intensity as a within-subject factor. Figure 2 shows the mean reactivity scores of each of the four handling and housing-condition groups across all stimulus intensities. The apparent housing $x$ handling interaction was short of conventional levels of statistical significance $[F(1,24)=3.58, p<$ $.07]$ while the main effects of housing $[F(1,24)=8.01$, $\mathrm{p}<.01]$ and handling $[\mathrm{F}(1,24)=4.29, \mathrm{p}<.05]$ were statistically significant. Thus, both handling and group housing were associated with lowered reactivity to the dorsal stimulation. However, Figure 2 and the interaction that was so close to statistical significance suggest that the group-housed animals were

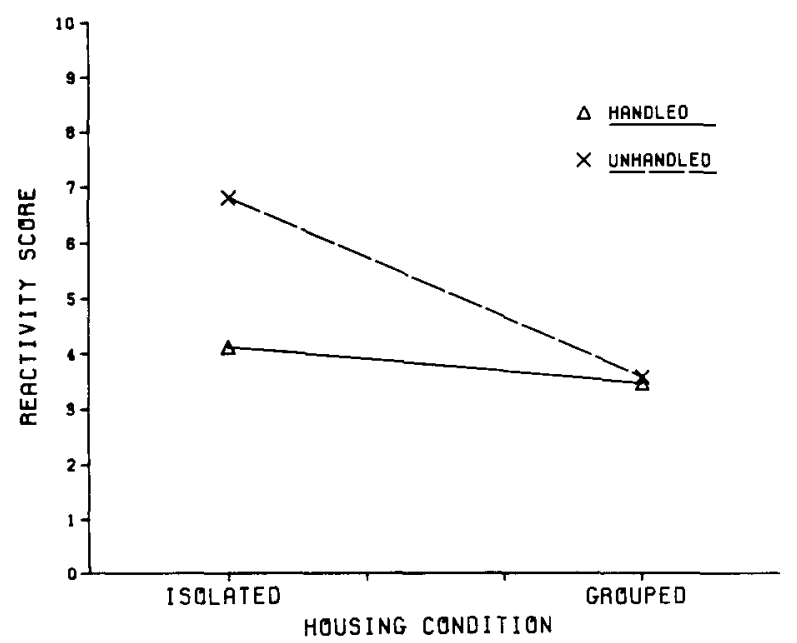

Figure 2. The mean responsivity scores of the four experimental groups of Experiment 1 based on all four airpuff intensities (psi). The responsivity score was the peak voltage output of the phono cartridge attached to the isometric startle platform.

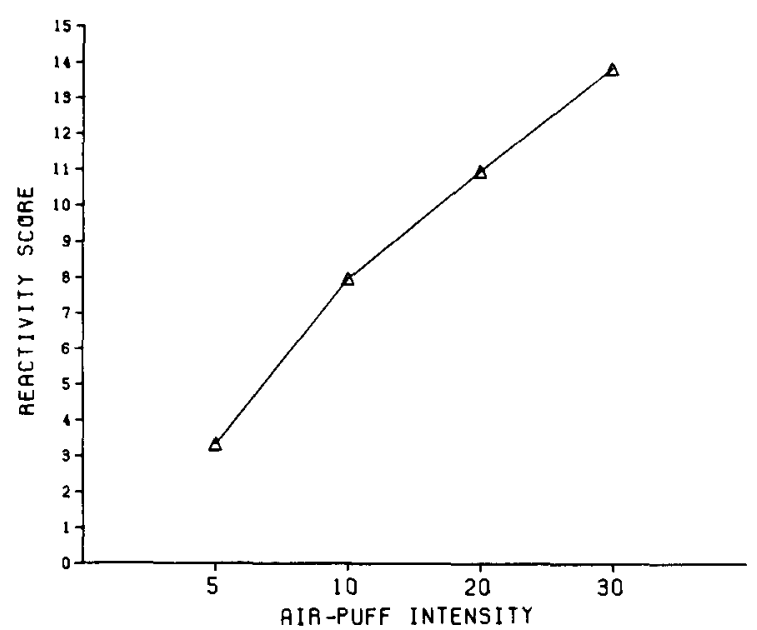

Figure 3. The mean responsivity score of all subjects of Experiment 2 at each of the four airpuff intensities. The responsivity score was the peak voltage output of the phono cartridge attached to the isometric startle platform.

relatively unreactive to dorsal stimulation and that the handling procedure produced only a minimal change in that performance. Furthermore, the data indicate that isolated animals were very reactive to dorsal tactile stimulation, but that the brief exposure to handling reduced their reactivity to almost the level of group-housed subjects.

As shown in Figure 3, the effect of airpuff intensity was statistically significant $[F(3,72)=63.64$, $\mathrm{p}<.001$ ], but, unlike the data of Experiment 1 , there were no statistically significant interactions of stimulus intensity with the experimental conditions.

\section{GENERAL DISCUSSION}

The results of these two experiments demonstrate the differential effects isolation housing and handling have on reactivity to two different stimuli. Isolation results in increased reactivity to nonpainful tactile stimulation of the dorsal surface at all of the intensities tested but results in increased reactivity to only the more intense shock stimuli used. The latter data are entirely consistent with previous work by Nelson and Knutson (1978), in which isolation resulted in greater reactivity to the more intense shock stimuli used in testing.

While the greater reactivity displayed by isolationreared rats to the more intense shock stimuli was unaffected by handling, the handling procedure rapidly eliminated the greater reactivity to airpuff stimuli by isolation-reared rats. This differential effect of handling on reactivity following isolation as a function of the test stimulus suggests that the greater reactivity to shock following a period of isolation is a relatively enduring pattern and the greater reactivity to dorsal tactile stimuli following isolation is an acute state. The enduring effects of isolation on reactivity to 
shock was suggested by Nelson and Knutson (1978), in whose study isolation resulted in increased reactivity to shock even after their rats had had 10 daily sessions of shock-induced aggression testing. Wahlstrand (1977) recently demonstrated that isolation early in development can result in greater reactivity to shock stimuli even after 30 days of groupcage housing. Thus, greater reactivity to intense shock following isolation seems to have a relatively long duration.

This long-lasting effect of isolation on reactivity to shock can be contrasted with the ease with which the isolation-induced hyperreactivity to airpuff stimuli can be eliminated with only $15 \mathrm{~min}$ of handling. Rats in group cages spend large amounts of time in close physical proximity and contact unless the ambient temperature is raised (e.g., Cairns, 1973). It should not be surprising that eliminating this physical contact for more than 3 months has a significant impact on reactivity. What is surprising is that the effects of isolation on reactivity could be eliminated with five daily 3 -min handling sessions. Such data suggest that the greater reactivity to tactile stimulation caused by isolation is extremely acute and that investigators should use great care in invoking reactivity to tactile stimulation to account for behavioral phenomena. Furthermore, the present data suggest that experimenters who are required to house animals in isolation could eliminate an unwanted effect of increased reactivity to tactile stimulation by using a relatively brief handling procedure.

The failure to show comparable influences of handling on reactivity to shock strongly suggests the lack of viability of a reactivity analysis of the different effects of handling on shock-motivated behavior. The precision of the isometric startle platform procedure and the small within-group variance that characterized the tests for reactivity to shock indicate that the failure to detect a handling influence in Experiment 1 is not due to problems of statistical power or precision. Because Experiment 2 provided support for Cairns's (1973) position that isolation renders rats hyperreactive to tactile stimulation, and because the data of Experiment 2 demonstrated that handling can eliminate this hyperreactivity, the results of Experiment 2 provide a basis for considering the results of Experiment 1 and ruling out altered reactivity as a function of handling in shock-motivated tasks. Quite simply, altered reactivity to shock as a function of handling is an untenable hypothesis to advance to account for the effects of handling on avoidance performance. Altered effects of reinforcement (e.g., McAllister et al., 1980), calming influences (Levis, 1970), altered activity, and reduced freezing (Wahlsten et al., 1968; Wahlsten \& Sharp, 1969) continue to be factors meriting further investigation.

\section{REFERENCES}

ADAMs, D. B. The relation of scent-marking, olfactory investigation, and specific postures in the isolation-induced fighting of rats. Behaviour, 1976, 56, 286-297.

Ahmad, S. S., \& Harvey, J. A. Long-term effects of septal lesions and social experience on shock-elicited fighting in rats. Journal of Comparative and Physiological Psychology, 1968, 66, 596-602.

Altman, H. B., \& Hommel, L. S. The reduction of avoidance behavior as a function of gentling. Psychonomic Science, 1969, 14, 91-92.

Bandler, R. J., JR., \& CHI, C. C. Effects of olfactory bulb removal on aggression: A reevaluation. Physiology \& Behavior, 1972, 8, 207-211.

Bartness, T. J., \& WaLdBILlig, R. J. Handling-induced changes in plasma volume and osmolality: Adrenal modulation of blood parameters. Physiology \& Behavior, 1981, 26, 177-182.

Bassett, J. R., Cainnchoss, K. D., \& King, M. G. Parameters of novelty shock predictability and response contingency in corticosterone release in the rat. Physiology \& Behavior, 1973, 10, $901-907$.

Bernstein, L. Effects of variation in handling upon learning and retention. Journal of Comparative and Physiological Psychology, $1957,50,162-167$

BratN, P. F., \& NowELl, N. W. Isolation versus grouping effects on adrenal and gonadal function in albino mice. I. The male. General Comparative Endocrinology, 1971, 16, 149-154.

CAIN, D. P. Olfactory bulbectomy: Neural structures involved in irritability and aggression in the male rat. Journal of Comparative and Physiological Psychology, 1974, 86, 213-220.

Carrss, R. B. Fighting and punishment from a developmental perspective. In J. K. Cole \& D. D. Jensen (Eds.), Nebraska Symposium on Motivation, 1972 (Vol. 21). Lincoln: University of Nebraska Press, 1973.

Candland, D. K., Faulds, B. D., Thomas, D. B., \& Candland, M. H. The reinforcing value of gentling. Journal of Comparative and Physiological Psychology, 1960, 53, 55-58.

Candland, D. K., Horowitz, S. H., \& Culbertson, J. Acquisition and retention of acquired avoidance with gentling as reinforcement. Journal of Comparative and Physiological Psychology, 1962, 55, 1062-1064.

Christre, R. Experimental naivete and experiential naivete. Psychological Bulletin, 1951, 4, 327-339.

Cunningham, C., Crowell, C. R., Eaton, N. K., \& Brown, J. S. A digital system for recording startle responses in small animals. Behavior Research Methods \& Instrumentation, 1973, $5,1-3$.

Degsí-Fulgheri, F., Lupo di Prisco, C., \& Verdarelli, P. Influence of long-term isolation on the production and metabolism of gonadal sex steroids in male and female rats. Physiology \& Behavior, 1975, 14, 495-499.

Einon, D. F., Morgan, M. J., \& Kibbler, C. C. Brief periods of socialization and later behavior in the rat. Developmental Psychobiology, 1978, 11, 213-225.

Flannelly, K. J., \& ThOR, D. H. Social experience and territorial aggression in rats: A replication with selected aggressive males. Journal of General Psychology, 1976, 95, 321-322.

Galvani, P. F. Air-puff-elicited startle: Habituation over trials and measurement of a hypothetical emotional response. Behavior Research Methods \& Instrumentation, 1970, 2, 232-233.

Goldsmith, J. F., Brain, P. F., \& Benton, D. Effects of age at differential housing and the duration of individual housing/ grouping on intermale fighting behavior and adrenocortical activity in TO strain mice. Aggressive Behavior, 1976, 2, 307-323.

Harlow, H., \& Zimmermann, R. R. Affectional responses in the infant monkey. Science, 1959, 130, $421-432$.

Hennessy, J. W., Levine, R., \& Levine, S. Influence of ex- 
perimental factors and gonadal hormones on pituitary-adrenal responses of the mouse to novelty and electric shock. Journal of Comparative and Physiological Psychology, 1977, 91, 770-777.

Hennessy, M. B., \& Levine, S. Sensitive pituitary-adrenal responsiveness to varying intensities of psychological stimulation. Physiology \& Behavior, 1978, 21, 295-297.

Hutzell, R. R., \& Knutson, J. F. A comparison of shockelicited fighting and shock-elicited biting in rats. Physiology \& Behavior, 1972, 8, 477-480.

KNUTSON, J. F., \& KANE, N. The effects of social isolation on two shock-induced aggressive responses in rats. Animal Learning \& Behavior, 1980, 8, 167-170.

LEvis, D. J. Between-trial transporting of animals: A methodological consideration. Behavior Research Methods \& Instrumentation, 1970, 2, 157-160.

Loizzo, A., \& MAssotTi, M. Taming effect of nonnarcotic analgesics on the septal syndrome in rats. Pharmacology, Biochemistry and Behavior, 1973, 1, 367-370.

Luciano, D., \& Lore, R. Aggression and social experience in domesticated rats. Journal of Comparative and Physiological Psychology, 1975, 88, 917-923.

McAllister, D. E., McAllister, W. R., Hampton, S. R., \& Scoles, M. T. Escape-from-fear performance as affected by handling method and an additional CS-shock treatment. Animal Learning \& Behavior, 1980, 8, 417-423.

MOYE R, K. E. Kinds of aggression and their physiological basis. Communications in Behavioural Biology, 1968, 2, 65-87.

Nelson, C., \& KNUtson, J. F. Sex, strain, and housing: Variables influencing the effects of prior shock exposure on shock-induced aggression. Aggressive Behavior, 1978, 4, 237-252.

Slotnick, B. M., \& McMullen, M. F. Intraspecific fighting in albino mice with septal forebrain lesions. Physiology \& Behavior, $1972,8,333-337$.
Sperling, S. E., \& VAlle, F. P. Handling-gentling as a positive secondary reinforcer. Journal of Experimental Psychology, $1964,67,573-576$.

Theios, J., Lynch, A. D., \& Lowe, W. F., JR. Differential effects of shock intensity on one-way and shuttle avoidance conditioning. Journal of Experimental Psychology, 1966, 72, 294-299.

Wahlsten, D., Cole, M., Sharp, D., \& Fantino, E. Facilitation of bar-press avoidance by handling during the intertrial interval. Journal of Comparative and Physiological Psychology, 1968, 65, 170-174.

WAHLSTEN, D., \& ShaRP, D. Improvement of shuttle avoidance by handling during the intertrial interval. Journal of Comparative and Physiological Psychology, 1969, 67, 252-259.

Wahlstrand, $\mathbf{K}$. The effects of isolation at two developmental periods on aggressive behavior in rats. Unpublished master's thesis, University of Iowa, 1977.

WELCH, A. S., \& WeLCH, B. L. Isolation, reactivity, and aggression: Evidence for an involvement of brain catecholamines and serotonin. In B. E. Eleftheriou \& J. P. Scott (Eds.), The physiology of aggression and defeat. New York: Plenum Press, 1971.

\section{NOTE}

1. A complete description of these experiments can be obtained from the first author. Drill-port burners can be obtained from Plumber's Supply, Iowa City, Iowa 52240.

(Manuscript received August 4, 1981; revision accepted for publication January 5,1982 .) 